JPDN ISSN 2579-6461 (Online) ISSN 2460-6324 (Print)

Jurnal Pendidikan Dasar Nusantara

Volume 5 | Nomor 2 | Januari $2020 \mid$

DOI: https://doi.org/10.29407/jpdn.v5i2.13854

\title{
PENGEMBANGAN MULTIMEDIA INTERAKTIF MACROMEDIA FLASH BERBASIS K-13 SEBAGAI INOVASI PEMBELAJARAN TEMATIK UNTUK SISWA SEKOLAH DASAR
}

\author{
Bagus Amirul Mukmin ${ }^{1}$, Nurita Primasatya ${ }^{2}$. \\ bagusamirulm@gmail.com ${ }^{1}$, nuritaprima@unpkediri.ac.id ${ }^{2}$ \\ Pendidikan Guru Sekolah Dasar \\ Fakultas Keguruan dan Ilmu Pendidikan \\ UN PGRI Kediri
}

\begin{abstract}
Abstrak: Pada jenjang Sekolah Dasar (SD) saat ini telah menggunakan Kurikulum 2013 (K-13) yang menekankan pada pembelajaran tematik dengan mempelajari berbagai bidang ilmu secara bersamaan dalam satu rangkaian tema. Tetapi permasalahnya adalah belum ada materi pembelajaran yang dikemas dalam bentuk multimedia interaktif yang mampu mengaitkan pembelajaran tematik K-13 di sekolah dasar.

Tujuan dari penelitian ini adalah menghasilkan produk multimedia interaktif berbasis K-13 sebagai inovasi pembelajaran tematik di sekolah dasar yang valid.

Jenis penelitian ini adalah jenis penelitian dan pengembangan (R\&D) dengan mengadaptasi model pengembangan ADDIE. Dikatakan mengadaptasi karena proses penelitian ini berhenti pada tahapan development yaitu dilihat dari segi validitas produk. Teknik pengumpulan data yaitu dengan cara observasi, wawancara, dan angket sedangkan analisis data dalam penelitian ini yaitu diskriptif kualitatif dan kuantitatif. Validitas produk berdasarkan ahli desain grafis mendapatakan skor 87 dengan kriteria valid. Sedangkan menurut ahli materi IPA produk ini mendapatkan skor 86 dengan kriteria valid. untuk ahli MTK mendapatkan skor 86, ahli materi bahasa Indonesia mendapatkan skor 90, dan pada materi PKN mendapatkan skor 89 dengan keterangan valid. Pada penilaian ahli materi PJOK mendapatkan skor 93 dengan kategori sangat valid. Dari segi kebahasaan multimedia ini mendapatkan penilaian sangat valid dan sesuai dengan tingkat perkembangan kognitif anak dengan nilai kevalidan 92. Dengan demikian kesimpulan dari penelitian ini yaitu produk multimedia interaktif berbasis K-13 ini dikatakan valid dan layak digunakan.
\end{abstract}

Kata kunci: Multimedia Interaktif, Kurikulum 2013, Pembelajaran Tematik

\section{THE DEVELOPMENT OF INTERACTIVE MULTIMEDIA MACROMEDIA FLASH BASED ON K-13 AS A THEMATIC LEARNING INNOVATION FOR THE STUDENTS OF ELEMENTARY SCHOOL}


Bagus, Nurita. Pengembangan Multimedia Interaktif Macromedia

Abstract: Currently at the elementary school level has used Curriculum 2013 (K-13) which emphasizes thematic learning by studying various fields of science simultaneously in a series of themes. But the problem is there is no learning material which is packaged in the form of interactive multimedia that is able to link K-13 thematic learning in elementary school.

The aim of this research is to produce interactive multimedia products based on $\mathrm{K}-13$ as a thematic learning innovation in valid primary schools.

The type of this research is a research and development $(R \& D)$ by adapting the ADDIE development model. It is said to adapt because this research process stops at the development stage in terms of product validity. Product validity based on graphic design experts score 87 with valid criteria. Meanwhile, according to Sciences experts this product got a score of 86 with valid criteria, for Mathematic experts it got a score of 86, Indonesian material experts got a score of 90, and Civics material received a score of 89 with valid information. In the expert assessment of Sports education received a score of 93 with a very valid category. From the multimedia linguistic point of view, the evaluation is very valid and appropriate to cognitive development level of children with a validity value of 92 . Thus the conclusion of this study is that interactive K-13 based multimedia products are said to be valid and feasible to use.

Keywords: Interactive Multimedia, Curriculum 2013, Thematic Learning

\section{PENDAHULUAN}

Seiring dengan perkembangan ilmu dan teknologi, manusia dituntut untuk menjadi manusia yang lebih matang dan maju sehingga dapat meneruskan perkembangan selanjutnya. Untuk menjadi manusia yang matang dan maju perlu adanya dukungan dari kemajuan dunia pendidikan, seperti sarana dan prasarana pendidikan yang sangat menunjang proses pembelajaran di Sekolah. Salah satunya fasilitas multimedia (komputer) yang sudah dimiliki oleh sekolah-sekolah SD di perkotaan, seperti Kota Kediri. Fasilitas teknologi tersebut juga dapat membantu guru dalam memudahkan pembelajaran, memotivasi dan mengakselerasi belajar siswa (Hardianto, 2013). Tetapi kenyataan di lapangan sangat berbeda, fasilitas multimedia (komputer) belum bisa dimanfaatkan secara maksimal. Penyebab dari permasalahan tersebut adalah belum ada materi pembelajaran yang dikemas dalam bentuk multimedia interaktif yang mampu mengaitkan pembelajaran tematik K-13 (Kurikulum 2013) di sekolah dasar. Berdasarkan wawancara yang telah dilakukan di SDI AL-Huda, guru dan siswa kelas IV menyatakan bahwa belum ada multimedia interaktif macromedia flash yang berbasis tematik K-13 di sekolah mereka. 
Bagus, Nurita. Pengembangan Multimedia Interaktif Macromedia

Selain itu sumber belajar yang ada hanya berupa buku paket dan itupun jumlahnya terbatas. Maka perlu adanya sebuah sumber belajar yang baru yang dapat dimanfaatkan oleh semua siswa seperti Multimedia interaktif macromedia flash. Multimedia ini sangat penting agar fasilitas TIK yang ada di sekolah tidak terbengkalai dan dapat dijadikan sumber belajar yang inovatif bagi siswa dan dapat membantu guru dalam menjelaskan materi pembelajaran K13. Sehingga teknologi ilmu komunikasi (TIK) sangat membantu proses pembelajaran yang ada di sekolah. Sejalan dengan (García, 2017) didalam penelitiannya menyatakan bahwa multimedia interaktif macromedia flash dalam bentuk animasi dirasa sangat membantu guru dalam menyampaikan materi di dalam kelas. Peryataan di atas didukung dengan hasil penelitian (Mukmin, 2018) yang menyatakan bahwa fasilitas TIK yang ada di sekolah dasar (SD) belum mampu dimanfaatkan secara maksimal sehingga berdampak terhadap hasil belajar siswa, selain itu bahan ajar yang digunakan juga tidak inovatif. Selain itu menurut (Aka, 2017) kehadiran TIK dalam dunia pendidikan memungkinkan terwujudnya pembelajaran yang efektif, menyenangkan, dan melibatkan siswa secara aktif. Sedangkan menurut (Hidayah, 2015) pembelajaran tematik sesuai dengan tahapan perkembangan anak, karakteristik cara anak belajar, konsep belajar dan pembelajaran bermakna, maka kegiatan pembelajaran bagi anak kelas awal SD sebaiknya dilakukan dengan pembelajaran temati. Menurut (Sungkono, 2006) pembelajaran tematik akan memberi peluang pembelajaran terpadu yang lebih menekankan pada partisipasi/keterlibatan siswa dalam belajar. Berdasarkan penelitian yang pernah dilakukan oleh (Nopriyanti, 2015) menyatakan bahwa produk multimedia pembelajaran interaktif efektif meningkatkan hasil belajar siswa. Dibuktikan dengan hasil bejara pada saat pretest nilai rata-rata hanya 63, sedangkan hasil rata-rata potest siswa setelah menggunakan produk tersebut menigkat menjadi 78 . Begitu pula dengan hasil penelitian yang dilakukan (Fibriani dkk, 2014) mengungkapkan bahwa hasil belajar dapat ditingkatkan dengan penggunaan multimedia interaktif pada pembelajaran. Pernyataan tersebut dibuktikan oleh nilai tes evaluasi yang menunjukkan persentase rerata nilai sebesar $86,06 \%$ dengan kriteria sangat efektif.

Berdasarkan permasalahan yang ada di atas yaitu pemanfaatan fasilitas sekolah yang terbengkalai karena tidak adanya sumber belajar TIK yang berbasis K13 dan sumber belajar yang ada saat ini tidak cukup bagi siswa. Maka untuk itu peneliti merasa perlu adanya sumber belajar baru yang memanfaatkan TIK, agar fasilitas yang ada di sekolah tidak terbengkalai. Dengan demikian peneliti bertujuan untuk mengembangkan multimedia 
Bagus, Nurita. Pengembangan Multimedia Interaktif Macromedia interaktif macromeidia flash yang berbasis K-13 untuk pembelajaran tematik pada siswa kelas IV sekolah dasar (SD).

\section{METODE}

Jenis metode penelitian yang digunakan dalam penelitian ini yaitu jenis metode penelitian pengembangan (Research and Development). Metode penelitian pengembangan (Research and Development) adalah metode penelitian yang digunakan untuk menghasilkan rancangan produk baru, menguji keefektifan produk yang telah ada, serta mengembangkan dan menciptakan produk baru.

Pada penelitian ini akan dihasilkan suatu produk media pembelajaran berbantuan komputer. Metode penelitian ini merujuk pada model ADDIE (Analysis, Design, Development, Implementation dan Evaluation) yang dikembangkan oleh Robert Maribe Branch (2009). Model Penelitian ADDIE oleh Robert Maribe Branch lebih terarah untuk mengembangkan media pembelajaran yang inovatif. Dalam penelitian ini produk yang dikembangkan merupakan media pembelajaran. Dengan berbagai pertimbangan, seperti penelitian hanya sampai pada uji kelayakan media, pengembangan media yang inovatif, dan hasil pengembangan yang dirasa lebih efektif maka peneliti menggunakan model penelitian ADDIE. Adapun rincian tahapannya sebagai berikut:

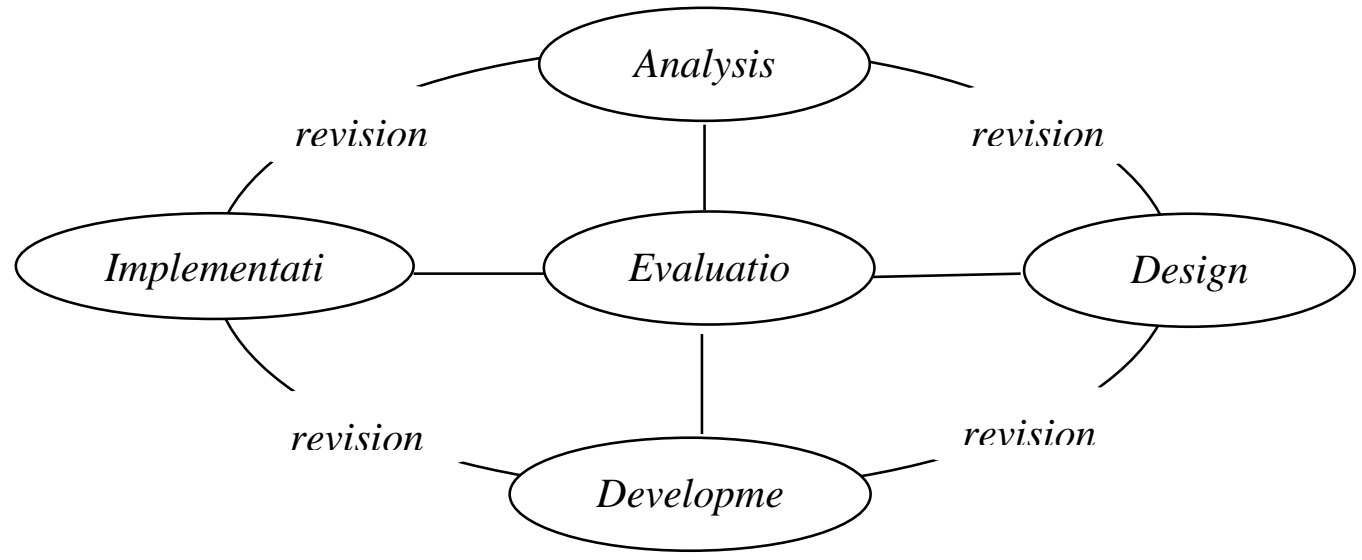

Bagan 2.1 Siklus Model Pengembangan ADDIE

Pada penelitian ini model pengembangan yang digunakan tidak sepenuhnya sama dengan model pengembangan ADDIE. Dalam penelitian ini tahapan penelitian berhenti pada tahapan Development yaitu pada tahapan validasi ahli. Sehingga model pengembangan yang digunakan merupakan modifikasi dari tahap pengembangan ADDIE. 


\section{Bagus, Nurita. Pengembangan Multimedia Interaktif Macromedia}

Berikut tahapan penelitian yang telah dikembangkan oleh peneliti yaitu mulai tahap analysis. Pada tahap analysis peneliti melakukan pengumpulan data dengan teknik wawancara kepala sekolah, guru, dan siswa terkait inovasi pembelajaran bagi siswa sekolah dasar. Selanjutnya setelah mendapatkan hasil analysis peneliti melakukan evaluasi untuk mengetahui sumber masalah yang ada di sekolah dasar. Setelah tahapan evaluasi dilakukan dan sudah menemukan solusi dari permsalahan yang ada maka dilakukan thapan desain. Pada tahap desain peneliti membuat sebuah jadwal perencanaan desain produk multimedia interaktif berbasis K-13. Mempersiapkan alat validasi untuk para ahli meliputi ahli materi, bahasa, desain grafis. Spesifikasi produk seperti menentukan spesifikasi bahan ajar untuk konsistensi tema, bentuk penulisan, interaksi dan umpan balik, serta warna, video, audio, animasi, latar belakang, menu, tomboltombol. Menyiapkan bahan isi materi untuk produk serta membuat petunjuk penggunaan multimedia interaktif macromedia flash. Selanjudnya menyusun dan mencari referensi untuk buku ajar tematik K-13 terkait tema pada produk. Setelah tahapan desain terlakasana makan dilakukan tahapan development. Pada tahap development peneliti membuat produk dan buku petunjuk penggunaan multimedia interaktif macromedia flast berbasis K13. Setelah produk jadi makan dilakukan tahapan evaluasi tahap 1 dimana pada tahap evaluasi yang pertama peneliti meminta masukan dan penilaian kepada para ahli terkait prodak yang telah peneliti kembangkan. Meliputi ahli materi IPA, MTK, PJOK, PPKN, Bahasa Indonesia, ahli desain grafis, dan ahli kebahasaan.

Setelah tahapan evaluasi 1 dilakukan makan peneliti melakukan tahapan revisi. Pada tahap revisi peneliti melakukan perbaikan sesuai dengan masukan dan saran dari para ahli. Sehingga menghasilkan produk yang sesui dengan tingkat perkembangan kognitif anak. Setelah produk selesai di revisi dan diperbaiki makan dilakukan evaluasi Tahap 2. Evaluasi tahap 2 bertujuan untuk memastikan bahwa produk yang dikembangakan sudah sesuai dengan masukan dan saran dari peneliti dan sudah sesuai dengan tingkat perkembangan siswa. Apabila sudah sesuai dan mendapatkan hasil yang sesuai kelayakan dari para ahli maka produk baru bisa dikatakan valid.

Pada tahap pengumpulan data peneliti menyiapkan instrument penelitian untuk mengetahui validitas produk. Instrument-intrumen tersebut meliputi angket validasi ahli materi IPA, MTK, PJOK, PPKN, Bahasa Indonesia, Desain grafis dan ahli Kebahasaan. Sedangkan teknik analisis data yang digunakan pada penelitian ini yaitu berupa analisis 
Bagus, Nurita. Pengembangan Multimedia Interaktif Macromedia data deskriptif kualitatif dan deskriptif kuantitatif. Analisis deskriptif kualitatif digunakan untuk mengolah data berupa angket validasi yang berupa respon dari para ahli, saran, dan masukan untuk perbaikan produk multimedia interaktif berbasis K-13 untuk siswa SD. Sedangkan deskriptif kuantitatif digunakan untuk mengolah data berupa hasil dari angket validasi ahli apakah multimedia interaktif berbasis K-13 layak digunakan.Memuat garis besar metode penelitian, prosedur pelaksanaan, alat, bahan, atau instrumen, dan teknik analisis. Jika diperlukan, ada informasi mengenai kisi-kisi instrumen. Bagian ini ditulis sebanyak $\pm 10-20 \%$ dari badan artikel.

\section{HASIL}

\section{A. Spesifikasi Produk Yang Dihasilkan}

Dalam penelitian pengembangan ini, peneliti mencoba mengembangkan sebuah produk multimedia interaktif yang berbasis kurikulum K-13. Produk multimedia interaktif ini disesuaikan dengan kurikulum K-13 yang ada di SD. Kurikulum K-13 merupakan kurikulum yang memadukan beberapa konsep mata pelajaran kedalam sebuah tema, pembelajarn yang dipadukan kedalam satu tema sering disebut dengan pembelajarn tematik. Pada tampilan pembuka multimedia interaktif berbasis K-13 berisikan judul, subyek, tema pembelajaran, sub tema, mata pelajaran yang sesuai dengan tema, dan terdapat tombol start untuk memulai penggunaan. Berikut contoh tampilan pembuka dapat dilihat pada gambar 5.1. Sedangkan Tampilan menu utama yaitu tampilan pada multimedia yang menampilkan menu-menu dan tombol-tombol dalam multimedia. Menu tersebut meliputi menu petunjuk, indikator, materi, kegiatan, kuis, profil, dan tombol keluar. Tampilan menu dapat dilihat pada gambar 5.2.

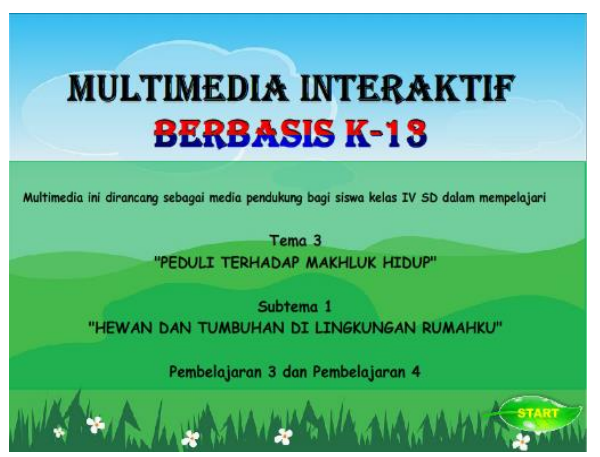

Gambar 5.1 Tampilan Awal Multimedia

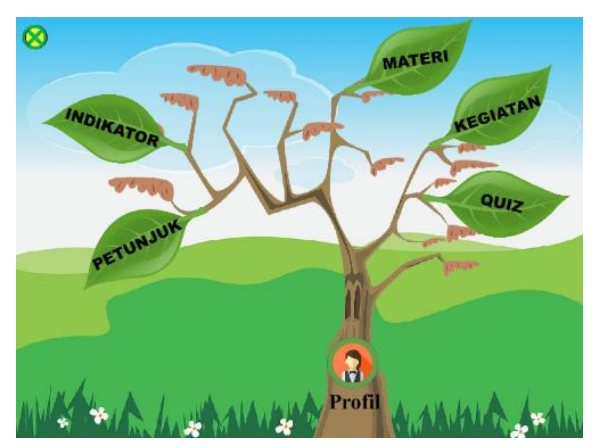

Gambar 5.2 Tampilan Menu Multimedia 


\section{Bagus, Nurita. Pengembangan Multimedia Interaktif Macromedia}

Pada menu petunjuk berisikan petunjuk terkait menu dan tombol yang ada pada multimedia. Menu indikator berfungsi untuk menampilan indikator dari pembelajaran yang akan dilakukan, yaitu terkait dengan tema 3 subtema 1 Pembelajaran 3 dan 4. Pada menu materi terdapat 2 pembelajaran yaitu pembelajaran 3 dan 4, sehingga terdapat pula tampilan yang menunjukkan tampilan dari materi-materi yang ada pada pembelajaran 3 dan 4. Materi tersebut meliputi PJOK, IPA, dan Bahasa Indonesia pada pembelajaran 3, serta PPKn, Matematika, dan Bahasa Indonesia pada pembelajaran 4. Tampilan tersebut terlihat pada gambar 5.3. dan 5.4.

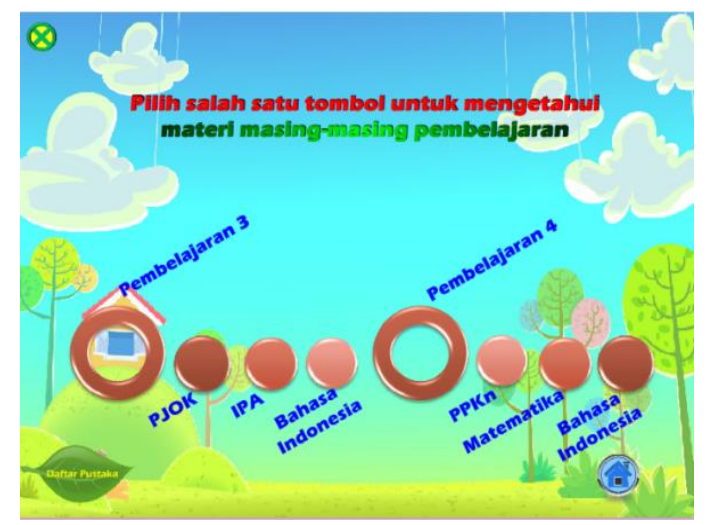

Gambar 5.3 Tampilan Menu Materi

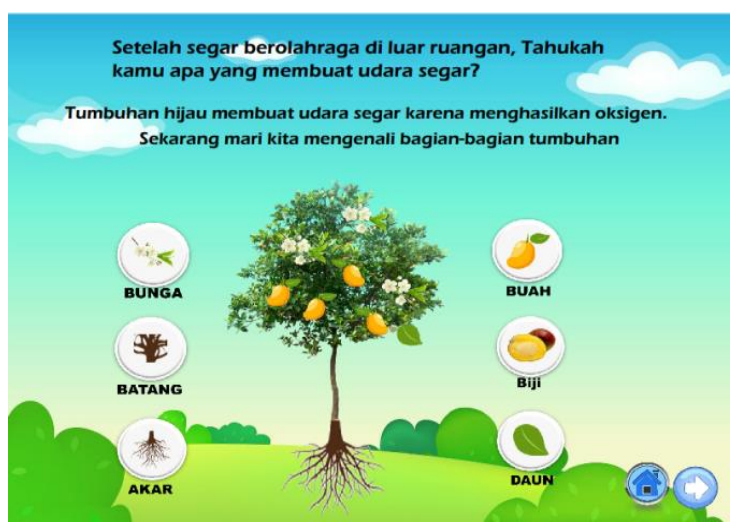

Gambar 5.4 Tampilan Materi

Dalam multimedia ini, terdapat audio berupa suara pada awal tampilan pembuka. Selain itu, terdapat pula suara yang muncul saat pengguna mengarahkan kursor pada tombol yang mungkin akan dipilih. Hal ini dilakukan supaya penggunaan multimedia tidak monoton. Penggunaan audio dalam multimedia ini juga bersifat instrumental dan bukan pada tampilan materi. Sehingga, pengguna tetap dapat berkonsentrasi saat mempelajari materi di multimedia interaktif ini. Sedangkan untuk tampilan gambar dan animasi di multimedia ini berfungsi memperjelas suatu materi sehingga tidak bersifat abstrak bagi siswa. Salah satu gambar yang ada pada multimedia ini seperti gambar 5.4 yang menyajikan gambar suatu pohon (tanaman) beserta bagian-bagianya. Selain itu, terdapat pula animasi seperti gambar 5.5 yang memberikan gambaran real terkait dengan permainan bola zig zag. 

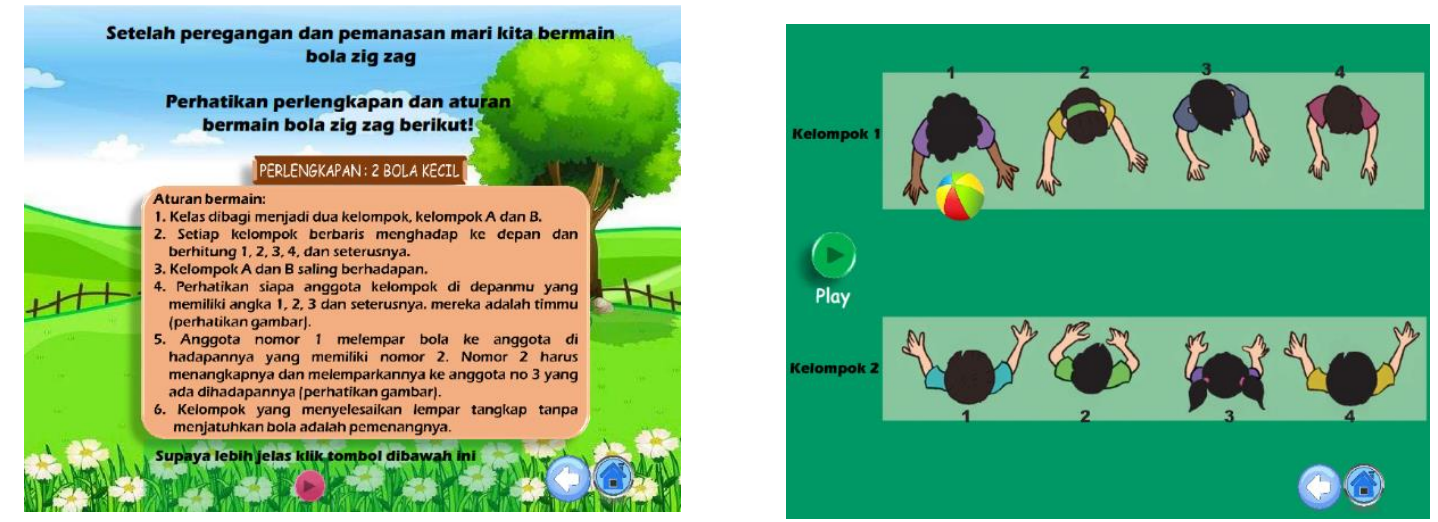

Gambar 5.5 Tampilan Materi PJOK (Bola Zig Zag) pada Pembelajaran 3

Bentuk tulisan dalam multimedia ini, digunakan beberapa jenis huruf yang berfungsi sebagai pembeda kalimat yang bersifat penjelasan atau kalimat yang bersifat instruksi. Jenis font yang digunakan diantaranya Comic Sand MS yang digunakan untuk memberikan intruksi kepada pengguna dan Eras Demi ITC yang digunakan untuk menjelaskan materi. Kedua jenis huruf tersebut dipilih dengan mempertimbangkan kemenarikan dan juga kesesuaian dengan perkembangan kognitif siswa kelas 4 SD.

Pemilihan background dan warna dalam multimedia ini disesuaikan dengan tema pembelajaran. Dalam multimedia ini dipelajari tema terkait dengan hewan dan tumbuhan di lingkungan sekitar, sehingga pemilihan background didominasi dengan tema lingkungan yang menampilkan tumbuhan. Sedangkan warna tombol dan lain sebagainya menyesuaikan dengan warna background, sehingga cenderung bersifat penuh warna. Hal ini juga sesuai dengan psikologi siswa kelas 4 SD yang lebih menyukai warna-marna terang yang dapat memberikan efek ceria.

Materi yang diambil dalam penelitian ini yaitu tematik kelas IV semester 1. Tema yang dipilih yaitu pada tema 3 sub tema 1 "hewan dan tumbuhan di lingkungan rumahku". Sedangkanpertemuan yang diambil yaitu pertemuan 3 dan pertemuan 4, mengapa peneliti hanya mengambil 2 pertemua karena keterbatasan waktu peneliti dan keterbatasan biaya yang dignakan. Pertemuan 3 terdiri dari materi PJOK, IPA, Bahasa Indonesia, sedangkan pada pertemuan 4 meliputi materi PPKN, MATEMATIKA, dan Bahasa Indonesia.

Soal kuis yang ada pada multimedia ini telah disesuaikan dengan indikator pembelajaran, sehingga setiap soal mencerminkan indikator yang ada. Soal tersebut 
Bagus, Nurita. Pengembangan Multimedia Interaktif Macromedia

terdiri dari 10 soal pilihan ganda dengan 4 jenis pilihan. Di tampilan awal kuis, terdapat kolom dimana siswa perlu mengisikan terlebih dahulu nama mereka. Selanjutnya, setelah selesai mengerjakan 10 soal yang ada, aka nada hasil yang menunjukkan perolehan skor mereka.

Dari beberapa tampilan tesebut, multimedia interaktif ini memiliki kelebihankelebihan yaitu selain memiliki animasi, menu-menu, dan tombol-tombol juga memwajibkan penggunanya lebih interaktif dalam penggunaanya sehingga pembelajaran menjadi lebih menarik dan bermakna. Sedangkan Menurut (Yanti dkk, 2017) dalam penelitiannya menyatakan bahwa keunggulan multimedia dengan alat bantu komputer menjadikan pembelajaran lebih bermakna karena multimedia mampu menyajikan suatu model pembelajaran yang interaktif.

\section{B. Penyajian Data Penelitian}

Data yang dihasilkan dalam penelitian ini yaitu data kevalidan produk dari ahli materi bahasa, ahli desain grafis, dan ahli materi. Ahli materi yang dipilih meliputi ahli materi IPA, Matematika, Bahasa Indonesia, PPKn, dan PJOK. Berikut hasil validitas produk berdasarkan beberapa ahli.

Hasil validitas produk berdasarkan ahli desain grafis tahap pertama yaitu bertujuan untuk mengetahui sejauh mana kevalidan multimedia ini. Pada tahap pertama ahli memberikan komentan bahwa penggunaan background terlalu ramai sehingga tulisan ada yang kurang terbaca. Selain itu penggunaan tombol dan tat letaknya kurang konsisten. Sedangkan dari hasil penilaian validitas berdasarkan lembar ceklis prokduk ini belum dikatakan valid karena mendatakan skor validitas sebesar 50 dengan kategori kurang valid. Pada tahap selanjutnya peneliti melakukan revisi berdasarkan masukan dan saran yang telah diberikan. Setelah produk direvisi selanjutnya di validasi lagi oleh ahli, dan mendapatkan skor kevalidan sebesar 87 dengan kategori valid digunakan dan mendapatkan komentar dari ahli layak digunakan. Dengan demikian berdasarkan ahli desain grafis produk multimedia interaktif berbasis K-13 layak digunakan dengan kategori valid.

Hasil validitas ahli bahasa didapatkan pada tahap pertama ahli bahasa memberikan komentar bahasa yang digunakan sulit dipahami dan bahasa yang digunakan belum sesuai dengan tingkat perkembangan kognitif anak. Saran yang diberikan yaitu 
Bagus, Nurita. Pengembangan Multimedia Interaktif Macromedia gunakan bahasa yang mudah dipahami dan sesuai dengan tingkat perkembangan kognitif anak. Sedangkan dari hasil penilaian validitas berdasarkan lembar ceklis produk ini sudah diktakan cukup valid, karena mendapatkan skor validitas sebesar 64. Pada tahap selanjutnya peneliti melakukan revisi berdasarkan masukan dan saran yang telah diberikan. Setelah produk direvisi selanjutnya di validasi lagi oleh ahli bahasa dan mendapatkan skor kevalidan sebesar 92 dengan kategori sangat valid digunakan dan mendapat komentar dari ahli layak digunakan. Dengan demikian berdasarkan ahli bahasa produk multimedia interaktif berbasis K-13 layak digunakan dengan kategori sangat valid.

Hasil validitas materi PJOK pada tahap validasi yang pertama memberikan saran dan masukan yaitu belum ada contoh animasi untuk pasing bola/ mengoper secara zigzag dan diminta untuk memberikan sebuah animasi bola zig-zag. Penilaian validitas dari ahli mendpatkan sekor 70 dengan keterangan cukup valid. Setelah mendapatkan masukan dan saran peneliti melakukan revisi yang diberikan oleh ahli. Setelah selesai direvisi peneliti meminta penilaian kembali untuk memastikan bahwa produk yang sudah direvisi layak. Validitas ahli pada tahap 2 ini mendapatkan sekor sebesar 93 dengan kriteria sangat valid dan mendapatkan komentar sudah layak untuk digunakan.

Hasil validitas materi IPA didapatkan berdasarkan penilian dari ahli materi IPA. Pada tahap pertama ahli memberikan komentan bahwa penggunaan animasi pohon, bunga, dan biji tidak realistis. Saran yang diberikan yaitu animasi pohon, daun, bunga, buah, dan biji harus realistis. Sedangkan dari hasil penilaian validitas berdasarkan lembar ceklis produk ini belum dikatakan valid karena mendatakan skor validitas sebesar 50 dengan kategori kurang valid. Tahap selanjutnya yaitu peneliti melakukan perbaikan berdasarkan saran dan masukan dari ahli. Setelah produk selesai direvisi maka dilakukan validasi tahap ke-2 dengan tujuan untuk mengetahui hasil yang kevalidan materi produk sebelum digunkan. Pada tahap validasi yang kedua didapatkan sekor kevalidan sebesar 
Bagus, Nurita. Pengembangan Multimedia Interaktif Macromedia 86 denga kategori valid digunakan. Berikut contoh gambar tampilan multimedia sebelum direvisi dapat dilihat pada gambar 5.6 dan gambar 5.7 setelah direvisi.

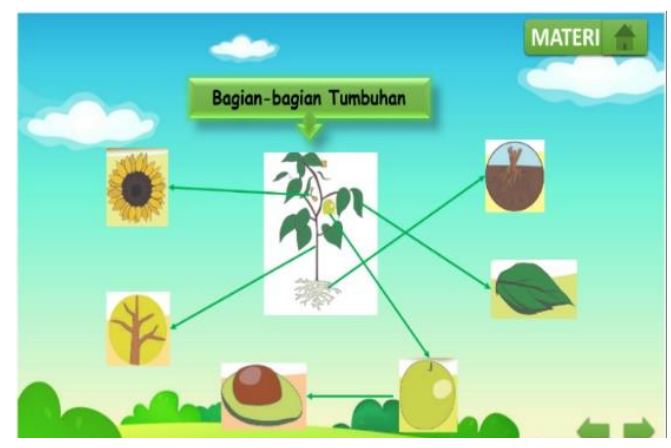

Gambar 5.6 Tampilan Sebelum Direvisi

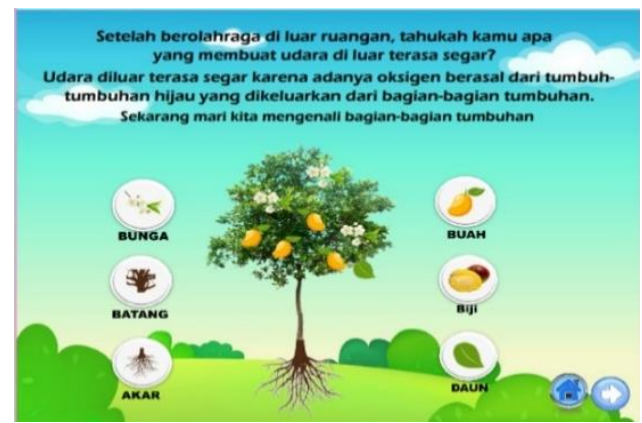

Gambar 5.7 Tampilan Sesudah Direvisi

Hasil validitas produk berdasarkan ahli materi Bahasa Indonesia pertama yaitu bertujuan untuk mengetahui sejauh mana kevalidanmultimedia ini digunakan. Pada tahap pertama ahli bahasa membarikan komentar bahwa masih ada kesalahan penulisan dan belum ada daftar pustaka. Saran yang diberikan yaitu perbaikan untuk kesalahan penulisan tersebut dan menyertakan daftar pustaka didalam multimedia. Sedangkan dari hasil penilaian validitas berdasarkan lembar ceklis produk ini sudah dikatakan valid, karena mendatakan skor validitas sebesar 70 dengan kategori valid. Pada tahap selanjutnya peneliti melakukan revisi berdasarkan masukan dan saran yang telah diberikan. Setelah produk direvisi selanjutnya di validasi lagi oleh ahli materi Bahasa Indonesia dan mendapatkan skor kevalidan sebesar 90 dengan kategori sangat valid digunakan dan mendapatkan komentar dari ahli layak digunakan. Dengan demikian berdasarkan ahli materi Bahasa Indonesia produk multimedia interaktif berbasis K-13 layak digunakan dengan kategori sangat valid.

Hasil validitas materi PPKN yaitu mendapatkan sekor 60 pada tahap 1 dengan keterangan cukup valid dan pada tahap 2 mendapatkan sekor 87 dengan kategori valid. Selain itu ahli materi juga memberikan masukan dan saran yaitu pada tahap 1 gambar sesuaikan dengan narasi atau cerita, panah seharusnya simetris, tulisan seharusnya didalam kotak secara rapi, tambah slaid kegiatan untuk KD psikomotor. Sedangkan pada tahap 2 ahli materi memberikan respon layak digunakan.

Hasil validitas materi matematika peneliti mendapatkan masukan dan saran dari ahli matematia. Pada tahap validasi pertama peneliti mendapatakan masukan dan 
Bagus, Nurita. Pengembangan Multimedia Interaktif Macromedia

komentar yaitu materi kurang mendalam. Selian itu tidak ada koneksi antara materi yang akan dipelajari dengan materi yang telah dipelajari. Pengayaan materi juga terlalu abstrak dan perlu divisualkan. Saran yang diberikan yaitu sajian materi dengan mendalam disertai contoh yang bervariasi agar siswa dapat mengkonstruksi pengetahuannya. Selain itu juga diminta untuk menambah apersepsi di bagian awal. Penilaian validitas pada tahap 1 mendapatkan sekor 41 dengan kategori kurang valid. Sedangkan pada tahap 2 mendapatkan skor 86 dengan kategori valid.

\section{PEMBAHASAN}

Berdasarkan hasil penelitian terbukti bahwa pengembangan multimedia interaktif macromedia flash berbasis K13 sebagai inovasi pembelajaran tematik pada siswa sekolah dasar valid. Kevalidan didapat berdasarkan ahli desain grafis, kebahasaan, IPA, MTK, PPKN, PJOK, dan ahli materi Bahasa Indonesia. Didukung dengan hasil penelitian (Sari, 2013) yang menyatakan bahwa metode pembelajaran yang dilakukan di sekolah dasar negeri sragen 12 menjadi lebih menarik dengan adanya media pembelajaran interaktif yang didukung dengan macromedia flash.Selain itu penelitian pengembangan ini bertujuan untuk meberikan sebuah inovasi pembelajaran yang memanfaatkan teknologi informasi dan komunikasi (TIK) untuk pembelajaran tematik bagi siswa SD. Menurut (Samintomo, 2012) menyatakan bahwa TIK menjadi alat yang sangat diperlukan untuk belajar, khususnya multimedia computer dan sumberdaya internet. Salah satunya yaitu pembelajaran menggunakan multimedia interaktif macromedia flash. Multimedia interaktif macromedia flas berbasis K-13 merupan sebuah inovasi yang baru dalam pembelajaran tematik yang ada dalam dunia pendidikan. Menurut (Yanti dkk, 2017) dalam penelitiannya menyatakan bahwa keunggulan multimedia dengan alat bantu komputer menjadikan pembelajaran lebih bermakna karena multimedia mampu menyajikan suatu model pembelajaran yang interaktif. Sedangkan menurut (Mukmin, 2018) pembelajaran mengunakan multimedia interaktif praktis digunakan dalam pembelajaran tematik bagi siswa SD.

Pembelajaran tematik merupakan pembelajarannya terpadu yang disusun berdasarkan konsep mata pelajaran serta tersusun berdasarkan beberapa tema. Setiap tema terdapat sub tema yang mana didalamnya terdapat beberapa pertemuan. Pembelajaran tematik bertujuan untuk memberikan pembelajaran yang bermakna kepada 
Bagus, Nurita. Pengembangan Multimedia Interaktif Macromedia

siswa. Peryataan diatas juga didukung oleh (Trianto, 2010:78) pembelajaran tematik dimaknai sebagai pembelajaran yang dirancang berdasarkan tema-tema tertentu, dalam pembahasan tema itu ditinjau dari berbagai mata pelajaran. Sedangkan menurut (Wahyuni dkk, 2016: 129) menyatakan bahwa pembelajaran tematik merupakan pembelajaran yang didasarkan dari sebuah tema yang digunakan untuk mengaitkan beberapa konsep mata pelajaran. Menurut (Chusni dkk, 2015) pembelajaran tematik itu pembelajaran yang dilakukan secara tematik terpadu dengan tujuan agar siswa mampu mengembangkan diri dan kompetensinya secara holistik dan bermakna.

Penelitian ini didukung oleh hasil penelitian (Mukmin, 2018: 156) yang menyatakan bahwa bahan ajar DELIKAN tematik berbasis multimedia interaktif valid menurut ahli materi, bahan ajar, dan ahli bahasa. Selain itu pembelajaran tematik berbasis multimedia interaktif sangat cocok untuk pembelajaran anak-anak kelas $\mathrm{V}$ selain menarik, mudah dipahami sehingga anak belajar secara maksimal. (Aka \& Sahari, 2017) dalam penelitiannya menyimpulkan bahwa bahan ajar multimedia interaktif dinilai sangat menarik, praktis, dan efektif dibuktikan bahwa produk ini dapat meminimalisir rendahnya hasil belajar siswa dengan nilai rata-rata siswa 85,2

Selain itu juga didukung oleh (Kurniawati \& Nita, 2018) yang menyatakan bahwa media pembelajaran berbasis multimedia interaktif untuk meningkatkan pemahaman konsep mahasiswa terbukti layak untuk digunakan dalam pembelajaran. Berdasarkan hasil penelitian yang telah didukung dari teori dan hasil penelitian terdahulu dapat dinyatakan bahwa multimedia interaktif berbasis K-13 ini layak digunakan karena sesuai dengan tingkat perkembangan kognitif anak baik dari segi bahasa, desain grafis, dan materi ke SDan.

\section{SIMPULAN}

Berdasarkan hasil penelitian yang telah dijelaskan di atas dapat disimpulkan bahwa multimedia interaktif macromedia flash berbasis K13 layak digunakan untuk pembelajaran tematik siswa sekolah dasar. Selain itu produk ini merupakan sumber belajar yang inovatif bagi siswa sekolah dasar karena masih sedikit sumber belajar K13 yang memanfaatkan TIK di sekolah. Sehingga produk ini nantinya memberikan kebaharuan terkait sumber belajar yang ada di SD. Produk ini memberikan dampak yang positif bagi pembelajaran tematik yang ada di sekolah dasar. Dimana nantinya dapat 
Bagus, Nurita. Pengembangan Multimedia Interaktif Macromedia dikembangkan dan di teraapkan di sekolah-sekolah dasar yang ada di kota kediri. Kelayakan produk ini berdasarkan hasil kevalidan yang diberikan oleh ahli desain grafis, IPA, MTK, Bahasa Indonesia, PPKN, PJOK, dan ahli Kebahasaan.

\section{UCAPAN TERIMA KASIH}

Ucapan trimakasih kepada kemenristek DIKTI yang sekarang menjadi kemendikbud yang telah memberikan hibah pendanaan untuk penelitian ini. Selain itu ucapan terimakasih juga peneliti sampaikan kepada semua yang membantu dalam penelitian ini yang tidak bisa peneliti sebutkan satu persatu.

\section{DAFTAR RUJUKAN}

Aka, K. A. (2017). Pemanfaatan Teknologi Informasi dan Komunikasi (TIK) Sebagai Wujud Inovasi Sumber Belajar di Sekolah Dasar. ELSE (Elementary School Education Journal): Jurnal Pendidikan dan Pembelajaran Sekolah Dasar, 1(2a).

Aka, K. A., \& Sahari, S. Pengembangan Bahan Ajar Multimedia Interaktif Pada Pembelajaran Pkn Kelas V Sekolah Dasar Berorientasi Teknik Klarifikasi Nilai. Jurnal Pendidikan Dasar Nusantara, 3(1), 70-96.

Atmawarni, U. M. A. (2016). PENGGUNAAN MULTIMEDIA INTERAKTIF GUNA MENCIPTAKAN PEMBELAJARAN YANG INOVATIF DI SEKOLAH. PERSPEKTIF, 1(1).

Akbar, S. 2013. Instrumen Perangkat Pembelajaran. Bandung: PT Remaja Rosdakarya

Branch, R, M. 2009. Instrucional Design-The ADDIE Approach. New york: Springer.

Chen, Y. T. (2012). The effect of thematic video-based instruction on learning and motivation in e-learning. International Journal of Physical Sciences, 7(6), 957965.

Chusni, M. M., Mahardika, A., \& Sukmarani, D. (2015). PENERAPAN KURIKULUM 2013 PADA PEMBELAJARAN TEMATIK SAINTIFIK DENGAN MEDIA LINGKUNGAN SEKOLAH UNTUK MENINGKATKAN KETERAMPILAN PROSES SAINS SISWA. Jurnal Pengajaran MIPA, 20(2), 186-190.

Darimi, I. (2017). Teknologi Informasi Dan Komunikasi Sebagai Media Pembelajaran Pendidikan Agama Islam Efektif. J. Pendidik. Teknol. Inf, 1(2), 111-121. 
Bagus, Nurita. Pengembangan Multimedia Interaktif Macromedia

Fibriani, L., Damris, M., \& Risnita, R. (2014). Pengembangan Multimedia Pembelajaran Interaktif untuk Meningkatkan Motivasi dan Hasil Belajar Siswa pada Materi Kesetimbangan Kimia SMA. Edu-Sains: Jurnal Pendidikan Matematika dan Ilmu Pengetahuan Alam Universitas Jember, 3(1).

Gunawan, G., Harjono, A., Sahidu, H., \& Sutrio, S. (2014). PENGGUNAAN MULTIMEDIA INTERAKTIF DALAM PEMBELAJARAN FISIKA DAN IMPLIKASINYA PADA PENGUASAAN KONSEP MAHASISWA. Jurnal Pijar Mipa, 9(1).

García, R. R., Quirós, J. S., Santos, R. G., González, S. M., \& Fernanz, S. M. (2007). Interactive multimedia animation with macromedia flash in descriptive geometry teaching. Computers \& Education, 49(3), 615-639.

Hamdani. 2011. Strategi Belajar Mengajar.Bandung: Pustaka Setia.

Husain, C. (2014). Pemanfaatan teknologi informasi dan komunikasi dalam pembelajaran di SMA Muhammadiyah Tarakan. Jurnal Kebijakan dan Pengembangan Pendidikan, 2(2).

Hidayah, N. (2015). Pembelajaran Tematik Integratif di Sekolah Dasar. Terampil: Jurnal Pendidikan dan Pembelajaran Dasar, 2(1), 34-49.

Indirani, F. (2016). Kompetensi pedagogik mahasiswa dalam mengelola pembelajaran tematik integratif kurikulum 2013 pada pengajaran micro di pgsd uad yogyakarta. Profesi Pendidikan Dasar, 2(2), 87-94.

Kurniawati, I. D. (2018). Media Pembelajaran Berbasis Multimedia Interaktif untuk Meningkatkan Pemahaman Konsep Mahasiswa. DOUBLECLICK: Journal of Computer and Information Technology, 1(2), 68-75.

Majid, Abdul. 2014. Strategi Pembelajaran. Bandung: PT Remaja Rosdakarya.

Mukmin, B. A., \& Zunaidah, F. N. (2018). Pengembangan Bahan Ajar DELIKAN Tematik Berbasis Multimedia Interaktif Untuk Siswa Sekolah Dasar di Kota Kediri. Al Ibtida: Jurnal Pendidikan Guru MI, 5(2), 145-158.

Nopriyanti, N., \& Sudira, P. (2015). Pengembangan multimedia pembelajaran interaktif kompetensi dasar pemasangan sistem penerangan dan wiring kelistrikan di SMK. Jurnal Pendidikan Vokasi, 5(2), 222-235. 
Bagus, Nurita. Pengembangan Multimedia Interaktif Macromedia

Sari, L. K., \& Sasongko, D. (2013, March). Media Pembelajaran Interaktif Bahasa Inggris Untuk Siswa Sekolah Dasar Kelas II. In Seruni-Seminar Riset Unggulan Nasional Inoformatika dan Komputer (Vol. 2, No. 1).

Setiawan, A. 2007. Dasar-dasar Multimedia Interaktif (MMI). Bandung: SPs UPI Bandung.

Sungkono, S. (2006). Pembelajaran Tematik dan Implementasinya di Sekolah Dasar. Majalah Ilmiah Pembelajaran, 2(1).

Sumintono, B., Wibowo, S. A., Mislan, N., \& Tiawa, D. H. (2012). Penggunaan teknologi informasi dan komunikasi dalam pengajaran: Survei pada guru-guru sains SMP di Indonesia. Jurnal Pengajaran MIPA, 17(1), 122-131.

Wahyuni, H. T., Setyosari, P., \& Kuswandi, D. (2017). Implementasi Pembelajaran Tematik Kelas 1 SD. Edcomtech Jurnal Kajian Teknologi Pendidikan, 1(2), 129136.

Yanti, H., Wahyuni, S., Maryani, M., \& Putra, P. D. A. (2017). PENGEMBANGAN MULTIMEDIA INTERAKTIF DISERTAI DRILLS PADA POKOK BAHASAN TEKANAN DI SMP. Jurnal Pembelajaran Fisika, 6(4), 348-355. 